\title{
PRIMARY NON-HODGKIN LYMPHOMA OF THE BREAST - A CASE REPORT AND REVIEW OF LITERATURE
}

\author{
Ashish Singhal1, Rahat Hadi², Namrata P. Awasthi3 ${ }^{3}$ Kiran Malhotra4, Charu Mahajan ${ }^{5}$
}

${ }^{1}$ Associate Professor, Department of Surgical Oncology, Dr. Ram Manohar Lohia Institute of Medical Sciences, Lucknow. ${ }^{2}$ Associate Professor, Department of Radiation Oncology, Dr. Ram Manohar Lohia Institute of Medical Sciences, Lucknow. ${ }^{3}$ Associate Professor, Department of Pathology, Dr. Ram Manohar Lohia Institute of Medical Sciences, Lucknow. ${ }_{4}^{4}$ Associate Professor, Department of Pathology, Dr. Ram Manohar Lohia Institute of Medical Sciences, Lucknow. ${ }^{5}$ Senior Resident, Department of Surgical Oncology, Dr. Ram Manohar Lohia Institute of Medical Sciences, Lucknow.

\section{ABSTRACT}

\section{BACKGROUND}

Primary breast lymphoma (PBL) is a rare but well-defined subtype of non-Hodgkin lymphoma (NHL) representing $0.5 \%$ of all malignant breast tumours, $1 \%$ of NHL and $2 \%$ of extra-nodal lymphomas. ${ }^{1}$ However, primary NHL (PNHL) is the most frequent hematopoietic tumour of the breast with diffuse large B-cell lymphoma (DLBCL) as the most common histological type. ${ }^{2}$ Clinical picture and imaging mimics carcinoma breast and diagnosis is usually established on biopsy. Chemotherapy and radiotherapy is the mainstay of treatment. The role of surgery is limited to biopsy to establish the correct histological diagnosis.

\section{KEYWORDS}

Lymphoma, Chemotherapy, Radiotherapy Surgery.

HOW TO CITE THIS ARTICLE: Singhal A, Hadi R, Awasthi NP, et al. Primary non-Hodgkin lymphoma of the breast - A case report and review of literature. J. Evolution Med. Dent. Sci. 2016;5(90):6742-6744, DOI: 10.14260/jemds/2016/1523

\section{BACKGROUND}

Primary breast lymphoma (PBL) is an uncommon disease with poor clinical outcome. PBL is used to define malignant lymphomas primarily occurring in the breast in the absence of previously detected lymphoma localisations. Wiseman and Liao are credited with defining the clinical criteria for PBL. ${ }^{3}$ The majority of PBL are diffuse large B-cell lymphomas (DLBCL), but other less frequent subtypes including mucosalassociated lymphoid tissue lymphoma, follicular lymphoma, Burkitt lymphoma and T-cell lymphoma. ${ }^{4}$ It appears that the prognosis of PB-DLBCL is generally comparable with that of nodal DLBCL and that standard treatment should consist of immunochemotherapy with an anthracycline-based regimen and include consolidation with radiotherapy especially in stage IE patients. ${ }^{4}$

\section{CASE REPORT}

The patient is a 65-year-old female, known diabetic and hypertensive, who presented to our outpatient department with a complaint of painless bilateral breast lumps since 3 months. There is no history of nipple discharge, weight loss, fever, night sweats or history suggestive of metastatic disease. Clinical examination revealed a $4 \times 3 \mathrm{~cm}$ lump in the right breast central quadrant and $2 \times 2 \mathrm{~cm}$ lump present in the left breast with restricted mobility. There were no palpable axillary or cervical lymph nodes. General and systemic examination was normal. Routine haematological and biochemistry were normal. Bilateral mammogram shows

Financial or Other, Competing Interest: None.

Submission 05-06-2016, Peer Review 29-10-2016,

Acceptance 04-11-2016, Published 10-11-2016.

Corresponding Author:

Dr. Ashish Singhal,

Department of Surgical Oncology,

Dr. RMLIMS, Vibhuti Khand

Gomti Nagar, Lucknow-226010

Uttar Pradesh.

E-mail: ashishpgi@yahoo.co.in

DOI: 10.14260/jemds/2016/1523 spiculated marginated heterogenous lesion with adjacent breast parenchymal invasion and architectural distortion in right breast with areas of nodularity at least two in left (opposite breast) (Fig. 1 \& 2). Fine needle aspiration cytology (FNAC) was done from both the lumps which were suggestive of haematolymphoid neoplasm with possible diagnosis of nonHodgkin lymphoma. Core biopsy was done from both lumps which show fibro-adipose tissue infiltrated by sheets of atypical lymphoid cells with medium to large, oval to round hyperchromatic nuclei with prominent nucleoli and scant cytoplasm with frequent mitosis. Immunohistochemistry was done which is consistent with the diagnosis of diffuse large $B$ cell non-Hodgkin lymphoma of the breast (LCA+, CD20+, CD3 -, PAN CK-, Ki67 60\%) (Fig 3). Bone marrow biopsy was normal. Positron emission tomography (PET CT) did not reveal any other sites of disease. Patient was administered 6 cycles of R-CHOP (Rituximab $375 \mathrm{mg} / \mathrm{m}^{2}$, Cyclophosphamide $750 \mathrm{mg} / \mathrm{m}^{2}$, Doxorubicin $50 \mathrm{mg} / \mathrm{m}^{2}$, Oncovin $1.4 \mathrm{mg} / \mathrm{m}^{2}$, with dose of prednisolone modified to $80 \mathrm{mg}$ because of her diabetes) following which her lesion resolved completely. Thereafter, she was administered external beam radiotherapy 50 Gray to both breasts. Patient has completed 9 months and is being followed with PET CT which did not reveal any areas of increased activity (Fig. 3).

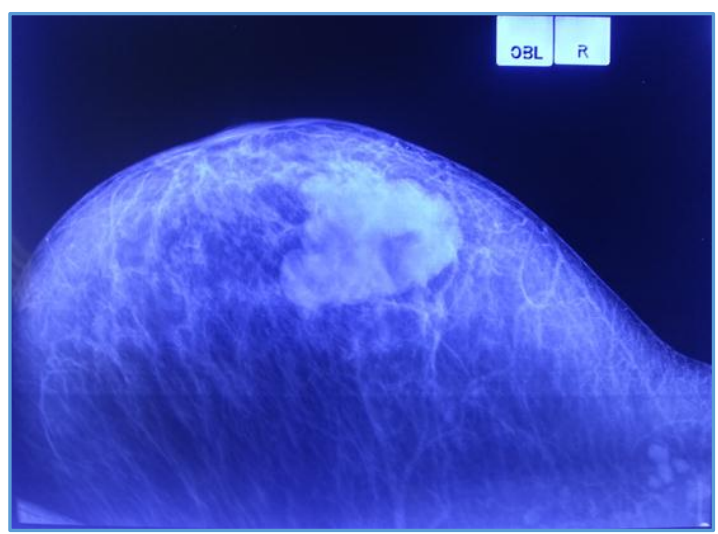

Figure 1. Right Mammogram showing Irregular Lobulated Lesion in the Central Quadrant 


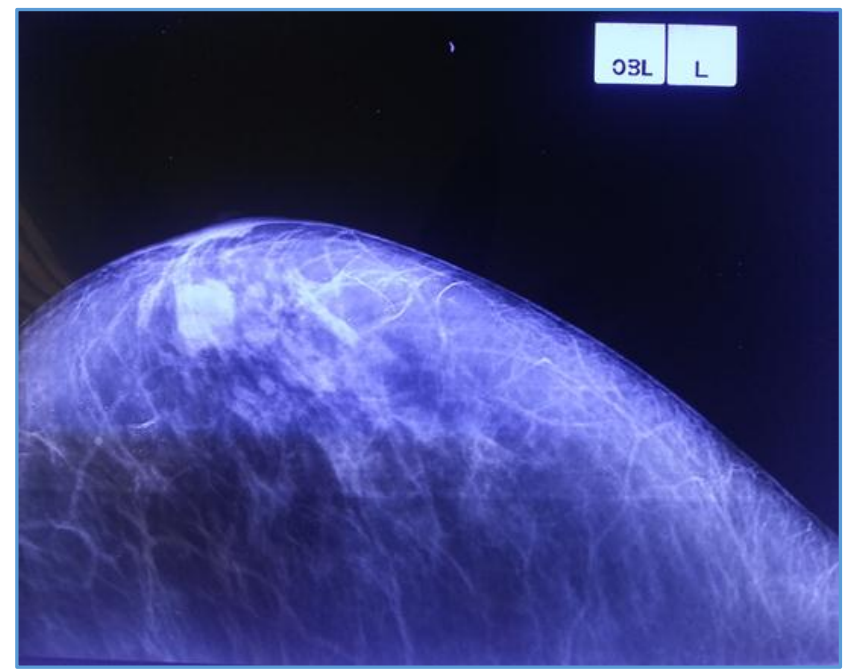

Figure 2. Left Mammogram showing Ill-defined Hyperdense Areas of Nodularity

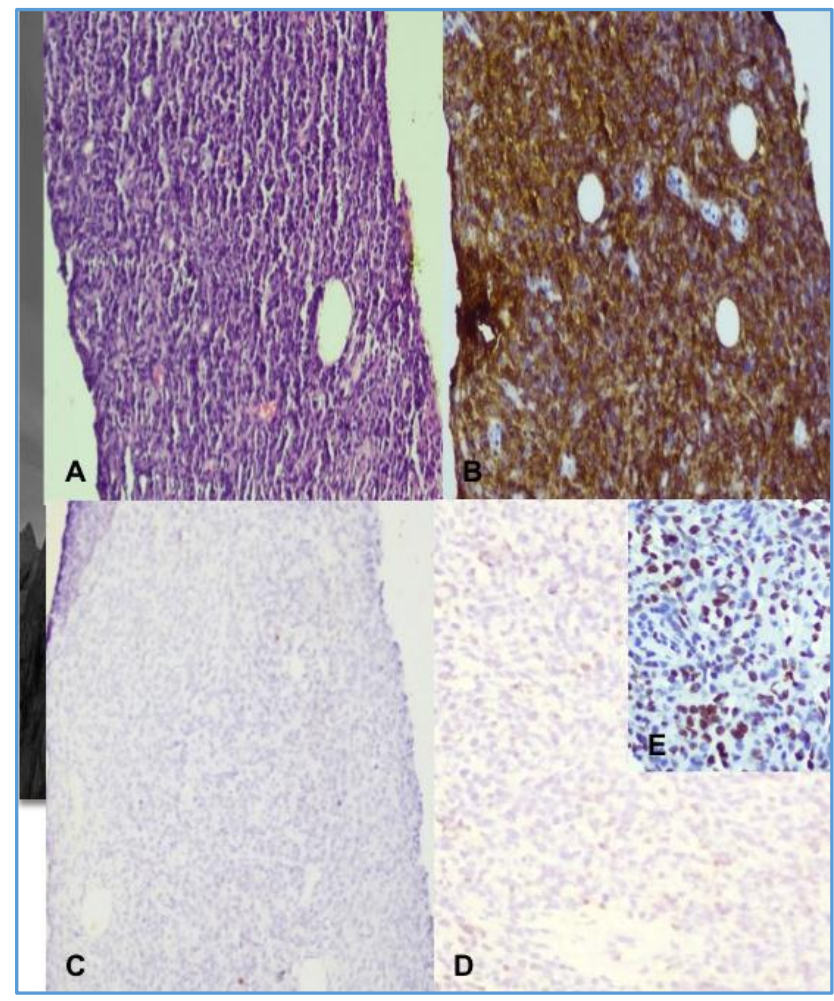

Figure 3. A: Shows Tumour composed of Large Round Cells Disposed in Sheets, Haematoxylin \& Eosin 100X; B: IHC for CD20 showing Diffuse Positivity in Tumour Cells; IHC for CD3 (C), Cytokeratin (D) showing Negative Staining in Tumour Cells: Ki67 IHC showing a Proliferation Index of $60 \%$.

\section{DISCUSSION}

Breast lymphoma is classified as primary or secondary (SBL). The term PBL is used when the breast is the principal and the only site of lymphoma. In 1972, Wiseman and $\mathrm{Liao}^{3}$ first defined PBL using four criteria: (i) mammary tissue and lymphoma must be in close anatomic proximity, (ii) no preceding diagnosis of extra-mammary lymphoma, (iii) no evidence of disseminated disease other than ipsilateral axillary lymphadenopathy, and (iv) adequate quality of the histopathological specimen. The usual clinical feature of a breast lymphoma is a rapidly expanding, painless mass with a slight predilection for the right breast, but the explanation for this remains unclear. ${ }^{5}$ Bilateral PBL accounts for 6 to $13 \%$ of all PBL and is still controversial with regard to stage and prognosis. ${ }^{6}$ For the sake of uniformity, and in view of a possible worse prognosis of bilateral PBL, these rare cases may well be classified as stage IV disease, whereas others have defined them as stage $\mathrm{I}_{\mathrm{E}}$ or II. ${ }^{7}$

As in other nodal forms of DLBCL, an anthracycline-based regimen is the mainstay of treatment, with CHOP being the most frequent regimen used for 4-6 cycles. Most PBL studies report favourably on the administration of systemic chemotherapy even for apparently localised disease. ${ }^{8}$

Radiotherapy appears to have a positive impact on the outcome of PB-DLBCL, especially in patients without axillary node involvement (stage $\mathrm{I}_{\mathrm{E}}$ ). The data on the role of irradiation for DLBCL in the rituximab era are still immature, but in light of results of the clinical trials and observations on PBL, we feel it should still be recommended as an adjuvant to systemic immunochemotherapy for localised disease. ${ }^{9}$

Surgery should be used for diagnosis only and must be minimally invasive as extensive surgery carries a high morbidity rate without any proven advantage over lumpectomy alone. Axillary dissection has no role in the treatment of PB-DLBCL. Surgery should not be regarded as a therapeutic modality, and if it has been performed due to the misdiagnosis of breast carcinoma, subsequent systemic therapy should always be given. ${ }^{4}$

The role of central nervous system (CNS) prophylaxis in DLBCL of the breast is controversial. There have been no prospective trials of CNS prophylaxis in this population. Case series have reported a high incidence of CNS recurrence, estimated at 12 to $27 \%$. Nevertheless, given this high incidence of CNS recurrence, central nervous system (CNS) prophylaxis should be considered. ${ }^{10}$

\section{CONCLUSION}

Primary and secondary lymphomas of the breast, though rare, should be considered in the differential diagnosis of breast malignancies. Flow cytometry and or biopsy is required to achieve the diagnosis. The rare possibility of occurrence of these tumours with high index of suspicion may prevent one from doing unnecessary mutilating surgery for a disease which can be cured by chemotherapy and radiotherapy.

\section{REFERENCES}

1. Validire P, Capovilla M, Asselain B, et al. Primary breast non-Hodgkin's lymphoma: a large single center study of initial characteristics, natural history and prognostic factors. Am J Hematol 2009;84(3):133-9.

2. Anuradha, Sinha A, Ramrakhiani D. Primary nonHodgkin's lymphoma of the breast: a case report. Acta Cytologica 2005;49(6):661-5.

3. Wiseman C, Liao KT. Primary lymphoma of the breast. Cancer 1972;29(6):1705-12.

4. Aviv A, Tadmor T, Polliack A. Primary diffuse large B-cell lymphoma of the breast: looking at pathogenesis, clinical issues and therapeutic options. Annals of Oncology 2013;24(9):2236-44.

5. Mouna B, Saber B, Tijani el H, et al. Primary malignant non-Hodgkin's lymphoma of the breast: a study of seven cases and literature review. World J Surg Oncol 2012;10:151. 
6. Lokesh KN, Sathyanarayanan V, Lakshmaiah KC, et al. Primary breast diffuse large B cell lymphoma- report of 6 cases from south India with review of literature. Indian J Surg Oncol 2013;4(4):368-73.

7. Fukuhara S, Watanabe T, Munakata W, et al. Bulky disease has an impact on outcomes in primary diffuse large B-cell lymphoma of the breast: a retrospective analysis at a single institution. Eur J Haematol 2011;87(5):434-40.

8. Zhao S, Zhang QY, Ma WJ, et al. Analysis of 31 cases of primary breast lymphoma: the effect of nodal involvement and microvascular density. Clin Lymphoma Myeloma Leuk 2011;11(1):33-7.
9. Aviles A, Delgado S, Nambo MJ, et al. Primary breast lymphoma: results of a controlled clinical trial. Oncology 2005;69(3):256-60.

10. Ryan G, Martinelli G, Kuper-Hommel M. et al. Primary diffuse large B-cell lymphoma of the breast: prognostic factors and outcomes of a study by the International Extranodal Lymphoma Study group. Ann Oncol 2008;19(2):233-41. 